\title{
Entender a las pandillas de América Latina: una revisión de la literatura
}

\author{
Understanding Gangs in Contemporary Latin America \\ Entendendo às Quadrilhas na América Latina: Uma revisão da literatura
}

\author{
DenNis Rodgers, ${ }^{*}$ Adam BairD ${ }^{* *}$
}

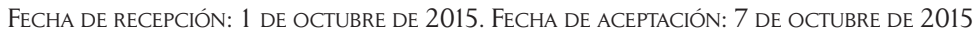

Doi: dx.doi.org/10.12804/esj18.01.2016.01

Para citar este artículo: Rodgers, D. y Baird, A. (2016). Entender a las pandillas en América Latina: una revisión de la literatura. Estudios Socio-Jurídicos, 18(1), 13-53. Doi: dx.doi.org/10.12804/esj 18.01.2016.01

\section{RESUMEN}

Este artículo tiene como objetivo brindar una visión general del conocimiento existente sobre las pandillas en América Latina. Ofrece una revisión de la literatura publicada basada en estudios empíricos primarios y comienza por las dos literaturas más desarrolladas hasta el momento en Centroamérica y Brasil y luego se considera la literatura de otros países de la región. Identificamos temáticas transversales importantes entre estudios, así como varias temáticas emergentes y proponemos una agenda para futuras investigaciones.

Palabras clave: pandillas, maras, mano dura, violencia urbana, violencia juvenil, delincuencia juvenil.

* Profesor catedrático de Estudios del Desarrollo Internacional, Facultad de Geografía Humana, Planificación y Desarrollo Internacional, Universidad de Ámsterdam (Holanda). Correo electrónico: d.w.rodgers@uva.nl

** Investigador del Centro para la confianza, la paz y las relaciones sociales, Universidad de Coventry (Reino Unido). Este artículo es una traducción de Rodgers, D. y Baird, A. (2015). Understanding Gangs in Contemporary Latin America. En S. H. Decker y D. C. Pyrooz (comps.), The Handbook of Gangs (pp. 478-502). Oxford: Wiley. Traducción del texto original por Diego Hakspiel, con retoques hechos por los autores. 


\section{ABSTRACT}

This article provides an overview of the current knowledge base about Latin American gangs drawing principally on studies based on primary empirical research. We begin by focusing on the two most developed bodies of work, respectively on Central American and Brazilian gangs, before then considering the emergent literature on several other countries in the region. We then go on to identify a range of long-standing, important cross-cutting themes, as well as several new ones, before concluding with a tentative agenda for future research.

Keywords: gangs, maras, mano dura, urban violence, youth violence, juvenile delinquency.

\section{RESUMO}

Este artigo tem como objetivo brindar uma visão geral do conhecimento existente sobre as quadrilhas na América Latina. Oferece uma revisão da literatura publicada baseada em estudos empíricos primários, começando pelas duas literaturas mais desenvolvidas até a data na América Central e o Brasil, antes de considerar literatura emergente em outros países da região. Identificamos temáticas transversais importantes entre estudos assim como várias temáticas emergentes, e propomos uma agenda tentativa para futuras pesquisas.

Palavras- chave: Quadrilhas, mano dura, violência urbana, violência juvenil, delinquência juvenil. 


\section{Introducción}

El pandillaje es considerado como uno de los mayores modos de violencia que afecta a las sociedades latinoamericanas contemporáneas. Sin embargo, no es un fenómeno nuevo: a finales del siglo XIX, las pandillas estaban muy presentes en las ciudades portuarias de Brasil (Soares, 2001) $\mathrm{y}$, desde hace muchos años, han servido como tema para películas como la clásica mexicana Los Olvidados, de la década del cincuenta. Su prominencia actual suele ser explicada como una consecuencia de las transformaciones que han afectado la economía política de violencia latinoamericana posterior a la Guerra Fría. En particular, se entiende como el reflejo de una transición desde un panorama dominado por conflictos ideológicos sobre la naturaleza del sistema político hacia formas más prosaicas de violencia como la delincuencia y el crimen (Kruijt y Koonings, 1999; Pearce, 1998). Aunque esta caracterización ha sido cuestionada por las continuidades de los patrones de violencia pasados y presentes (Rodgers, 2009), no cabe duda de que América Latina es una de las regiones más violentas en el mundo, con tasas nacionales de homicidio que sobrepasan a zonas de guerras y conflicto alrededor del mundo (Small Arms Survey, 2013).

No sorprende, entonces, que la violencia y la inseguridad se hubieran convertido en problemáticas políticas de la zona (Arias y Goldstein, 2010; World Bank, 2011) y que las pandillas se transformaran en focos de interés. Jones y Rodgers (2011) señalan que las pandillas han remplazado al comunismo como la mayor "amenaza" para la democracia en América Latina desde el fin de la Guerra Fría y han servido como incentivo para intervenciones particulares, incluida una extensiva represión punitiva y una "securitización"1 de las políticas de desarrollo. Al mismo tiempo, existe un sensacionalismo significativo en torno al tema. Como en varios países del mundo, las pandillas no son un fenómeno social unitario. El término "pandilla" se utiliza para denotar una amplia gama de formas sociales, desde grupos de jóvenes en esquinas, hasta asociaciones de crimen organizado. En efecto, uno de los mayores problemas al discutir sobre las pandillas latinoamericanas es la fusión generalizada entre estas y el crimen organizado,

1 Esta palabra específica en nuestra disciplina, del inglés "securitization", quiere decir que el desarrollo ha sido cooptado por la seguridad. 
alimentada por reportajes mediáticos amarillistas. Aunque no hay duda de los lazos entre las pandillas, los traficantes de drogas y el crimen organizado, estos no son preordenados y esta conexión es más asumida que demostrada. En los casos en los que existen, suelen ser opacas, complejas y cambiantes de un contexto a otro.

Nuestro conocimiento acerca de las pandillas, los traficantes de drogas y el crimen organizado es bastante inconsistente $y$, a menudo, contradictorio; por eso, este artículo tiene como objetivo brindar una visión general acerca de este asunto. ${ }^{2}$ Ofrece una revisión de la literatura publicada fundada en estudios empíricos primarios, porque, pese a que existen buenos estudios basados en fuentes secundarias, la mayoría suele ser sensacionalista, con motivaciones políticas, especulativa y, en ocasiones, errada. ${ }^{3}$ Comenzaremos enfocándonos en las dos literaturas más desarrolladas hasta el momento en Centroamérica y Brasil, así como en la literatura emergente en otros países de la región (tabla 1). A continuación, identificaremos la continuidad de temáticas transversales importantes entre estudios y varias temáticas emergentes y concluiremos con una agenda tentativa para futuras investigaciones.

Tabla 1. Estudios seleccionados acerca de pandillas latinoamericanas basados en investigación primaria

\begin{tabular}{|c|l|l|}
\hline \multicolumn{1}{|c|}{ País } & \multicolumn{1}{|c|}{ Ciudad } & \multicolumn{1}{c|}{ Investigaciones } \\
\hline \multirow{5}{*}{ Brasil } & Brasilia & Abramovay, Waiselfisz, Andrade y das Graças Rua (2002). \\
\cline { 2 - 3 } & Fortaleza & Garmany (2011). \\
\cline { 2 - 3 } & & $\begin{array}{l}\text { Arias (2004; 2006; 2014); Arias y Davis Rodrigues (2006); } \\
\text { Dowdney (2003; 2007); Gay (2005; 2009; 2010); Golds- } \\
\text { tein (2003); Hume y Wilding (2015); Leeds (1996; 2007); } \\
\text { Penglase (2005; 2008; 2009); Perlman (2009); Soares, Sé, } \\
\text { Rodrigues y Piquet Cerneiro (1996); Vianna (1997); Zaluar } \\
\text { (1983; 1994; 1997; 2000). }\end{array}$ \\
\hline
\end{tabular}

2 Este artículo excluye el Caribe.

3 Consideramos estudios empíricos primarios a aquellos basados en un trabajo de campo durante el cual los investigadores han tenido un intercambio sostenido con pandilleros o gente directamente afectada por pandilleros. Descartamos estudios basados en encuestas e investigaciones fundadas en el análisis de textos. Los trabajos discutidos en este artículo han sido seleccionados por los conocimientos de los autores - quienes llevan muchos años desarrollando estudios sobre pandillas en países latinoamericanos (Nicaragua y Colombia) - y también por una búsqueda literaria clásica mediante el uso de herramientas como Google Scholar, IBSS y Web of Knowledge. 


\begin{tabular}{|c|c|c|}
\hline País & Ciudad & Investigaciones \\
\hline Brasil & São Paulo & $\begin{array}{l}\text { Adorno, De Lima, Feiguin, Biderman y Bordini (1998); } \\
\text { Denyer Willis (2009; 2014; 2015). }\end{array}$ \\
\hline \multirow{4}{*}{ Colombia } & Bogotá & Perea Restrepo (2007). \\
\hline & Barranquilla & Perea Restrepo (2007). \\
\hline & Neiva & Perea Restrepo (2007). \\
\hline & Medellín & $\begin{array}{l}\text { Aricapa (2005); Baird (2009; 2012a; 2012b; 2015b); Riaño- } \\
\text { Alcalá (2006). }\end{array}$ \\
\hline \multirow[b]{2}{*}{ Ecuador } & Guayaquil & Moser (2009); Santillán y Varea (2008); Torres (2006). \\
\hline & Quito & $\begin{array}{l}\text { Cerbino (2012); Cerbino y Barrios (2008); Cerbino y Rodrí- } \\
\text { guez (2008); Santillán y Varea (2008). }\end{array}$ \\
\hline El Salvador & San Salvador & $\begin{array}{l}\text { Aguilar (2006); Brenneman (2012); Cruz (2005, 2010, } \\
\text { 2014); Cruz y Portillo Peña (1998); DeCesare (1998); } \\
\text { Demoscopía (2007); Hume (2004; 2007a; 2007b; 2009); } \\
\text { Hume y Wilding (2015); Núñez (1996); Rubio (2007); San- } \\
\text { tacruz Giralt y Concha-Eastman (2001); Savenije (2009); } \\
\text { Savenije y Andrade-Eekhoff (2003); Wolf (2012a; 2012b); } \\
\text { Zilberg (2011). }\end{array}$ \\
\hline Guatemala & $\begin{array}{l}\text { Ciudad de Guate- } \\
\text { mala }\end{array}$ & $\begin{array}{l}\text { Brenneman (2012); DeCesare (2013); Demoscopía (2007); } \\
\text { Grassi (2011); Levenson (1988; 2013); Merino (2001); } \\
\text { Núñez (1996); O’Neill (2010; 2011; 2012); Ranum (2011); } \\
\text { Rubio (2007); Winton (2004; 2007). }\end{array}$ \\
\hline Honduras & Tegucigalpa & $\begin{array}{l}\text { Brenneman (2012); Castro y Carranza (2001); Demoscopía } \\
\text { (2007); Gutiérrez Rivera (2010; 2013); Rubio (2007); Salo- } \\
\text { món, Castellanos y Flores (1999); Wolseth (2011). }\end{array}$ \\
\hline Nicaragua & Managua & $\begin{array}{l}\text { Bolognesi (2009); Núñez (1996); Rocha (2000a; 2000b; } \\
\text { 2003; 2005; 2007a; 2007b; 2008a; 2008b; 2010; 2013); } \\
\text { Rocha y Rodgers (2008); Rodgers (1997; 2000; 2006a; } \\
\text { 2007a; 2007b; 2009; 2010; 2013; 2015a; 2015b); Rodgers } \\
\text { y Rocha (2013); Rubio (2007); Sosa Meléndez (2000); } \\
\text { Ulloa (2004); Vermeij (2006); Weegels (2014). }\end{array}$ \\
\hline \multirow{4}{*}{ México } & Guadalajara & Reguillo (1991). \\
\hline & México D. F. & $\begin{array}{l}\text { Castillo Berthier (2002; 2004); Castillo Berthier y Jones } \\
\text { (2009); Cruz Salazar (2004); Gigengack (2006); Nateras } \\
\text { Domínguez (2006); Perea Restrepo (2007). }\end{array}$ \\
\hline & Monterrey & Hernández León (1999). \\
\hline & Puebla & Herrera, Jones y Thomas de Benítez (2009); Jones (2014). \\
\hline Venezuela & Caracas & $\begin{array}{l}\text { Mateo y González (1998); Pedrazzini y Sánchez (1992); } \\
\text { Zubillaga (2007; 2009; 2013); Zubillaga y Briceño-León } \\
\text { (2001); Zubillaga, Llorens y Souto (2015). }\end{array}$ \\
\hline
\end{tabular}

Fuente: elaboración propia. 


\section{Pandillas en Centroamérica}

Aunque las pandillas juveniles en Centroamérica se remontan a las décadas del cuarenta y del cincuenta, junto con la industrialización de la región que trajo consigo la urbanización, la primera investigación a profundidad de este fenómeno no se desarrolló sino hasta finales de la década del ochenta. Deborah Levenson (1988) fue pionera con su investigación sobre las pandillas callejeras en Guatemala, con la cual sentó las bases para el estudio comparativo de pandillas callejeras en Guatemala, El Salvador y Nicaragua, realizado por Juan Carlos Núñez (1996); sobre El Salvador, por Donna DeCesare (1998) y José Miguel Cruz y Nelson Portillo Peña (1998) y sobre Honduras, por Leticia Salomón, Julieta Castellanos y Mirna Flores (1999).

El primer estudio verdaderamente etnográfico sobre pandillas juveniles latinoamericanas se hizo entre 1996 y 1997 por Dennis Rodgers (1997; $2000 ; 2007 a)$ en Nicaragua. Este fue profundizado por José Luis Rocha (2000a; 2000b; 2003; 2005) durante su investigación en Managua, entre los años de 1999 y 2000; sus resultados fueron analizados por Rodgers (2006a; 2007b), con el propósito de calibrar nuevos trabajos de campo desarrollados entre 2002 y 2003. Rocha continuó sus estudios entre 20052006 y 2012 (Rocha, 2007a; 2007b; 2008a; 2008b; 2010; 2013); Rodgers, en 2007, 2009, 2012 y 2014 (Rodgers, 2010; 2013; 2015a, 2015b) y ambos hicieron una investigación comparativa en 2012 (Rodgers y Rocha, 2013). ${ }^{4}$

En esta primera ola de investigaciones académicas, se observa un número creciente de investigadores que, en su mayoría, han ubicado su fuente en los trabajos mencionados. Se destacan Santacruz Giralt y Concha-Eastman (2001), Savenije y Andrade-Eekhoff (2003), Cruz (2005; 2010; 2014), Hume (2007a; 2007b; 2009), Savenije (2009) y Wolf (2012a; 2012b) en El Salvador; Castro y Carranza (2001), Gutiérrez Rivera (2010; 2013) y Wolseth (2011) en Honduras; Bolognesi (2009), Sosa Meléndez (2000), Ulloa (2004), Vermeij (2006) y Weegels (2014) en Nicaragua; Merino (2001), Winton (2004), O’Neill (2010; 2011; 2012) y Levenson (2013) en Guatemala; por último, Zilberg (2011) hizo un estudio transnacional de

4 Nicaragua es el país centroamericano que ha sido estudiado con mayor atención empírica, debido a la conversación longitudinal y etnográfica entre Rocha y Rodgers (2008). 
pandillas entre Los Ángeles y El Salvador. También existe un compendio de múltiples volúmenes dedicado a cada país centroamericano, publicado a mediados de la década de 2000 por un conglomerado de institutos de investigación regional (ERIC, Ideso, Idies e Iudop, 2001; 2004; ERIC, Ideso, Iudop, Nitlapan y Dirinpro, 2004). A esto se suman cuatro estudios generales basados en investigación primaria (aunque de calidad variable): USAID (2006); Demoscopía (2007); el proyecto sobre "Pandillas juveniles transnacionales en Centroamérica, México y los Estados Unidos", coordinado por el Centro de Estudios y Programas Interamericanos (CEPI) del Instituto Tecnológico Autónomo de México (ITAM) ${ }^{5}$ y el tomo editado por Thomas Bruneau, Lucía Dammert y Elizabeth Skinner (2011). ${ }^{6}$

De ahí se desprende un número de observaciones clave sobre las pandillas en Centroamérica, incluido el hecho de que las pandillas son asociadas con la pobreza por el contexto, mas no por la causa, que se pueden establecer conexiones estructurales entre el período posterior a la Guerra Fría, la aparición de pandillas y la larga historia de insurrección y resistencia contra la opresión en la región y que un solo factor no explica la pertenencia a una pandilla o el curso de vida de los individuos, una vez la abandonan. Se ha reportado que estereotipos "determinantes" como la fragmentación familiar, el abuso doméstico o las afectaciones psicológicas no son factores consistentemente significativos y la religión es el único elemento que ha reportado una afectación sistemática en la vinculación con las pandillas. En efecto, se ha encontrado que los jóvenes evangélicos no tienden a involucrarse a las pandillas y que la conversión evangélica es uno de los medios más comunes para dejarlas, sea porque es una de las pocas estrategias de salida existentes, junto con la muerte y la migración -como ocurre en El Salvador, Guatemala y Honduras- o porque les permite adoptar una nueva personalidad distante de los patrones de comportamiento pandillero -como en Nicaragua-.

5 Para ampliar información sobre este grupo, puede verse http://interamericanos.itam.mx/ maras/index.html

6 No consideramos la multitud de resúmenes superficiales que se han escrito con base en literatura secundaria y tampoco estudios que apenas aluden a pandillas dentro de una investigación más amplia, como el asunto más amplio de violencia de juventud en América Latina (Jones y Rodgers, 2009). 
Sin embargo, la observación más importante es la escasez de información oficial confiable acerca de las pandillas en Centroamérica, con estadísticas nacionales que subestiman la problemática, con recopilación de datos deficientes e incidentes de interferencia política consecuentes con el hecho de que las pandillas se han convertido en "chivos expiatorios" señalados como la mayor causa de miseria. Este alarmismo desconoce la existencia de una diversidad significativa entre pandillas y países en la región. Por ejemplo, existe una distinción crítica entre pandillas y maras, entendidas estas últimas como un fenómeno con raíces transnacionales diferente de las pandillas, cuyo carácter es más localizado y nacional, herederas directas de las pandillas juveniles tradicionales de la región, aunque cargadas por el legado de guerra e insurrección en la región. Las pandillas tuvieron una presencia inicial en toda la zona en el período posterior a la Guerra Fría, pero en la actualidad solo cuentan con una significativa presencia en Nicaragua y, a menor escala, en Costa Rica, porque han sido remplazadas casi en su totalidad por las maras en El Salvador, Honduras y Guatemala; no obstante, cabe anotar que, en ese último país, las maras también involucran grupos asumidos como pandillas en otros países de la región (Grassi, 2011).

Los orígenes de las maras se remontan a la pandilla Dieciocho o 18th Street, fundada por inmigrantes mexicanos en la sección Rampart de la ciudad de Los Ángeles, en la década del sesenta, la cual aumentó su tamaño a finales de la década del setenta y principios de la del ochenta, al aceptar hispanos - en su mayoría, salvadoreños y guatemaltecos (refugiados) - que buscaban un sentido de inclusión como extranjeros en Estados Unidos (Valdez, 2011). En la segunda mitad de la década del ochenta surgió un grupo rival (quizás desertor), fundado por una segunda ola de refugiados salvadoreños, y recibió el nombre de mara Salvatrucha (combinación de "salvadoreño" y "trucha", que significa hábil o astuto, en jerga salvadoreña). La Dieciocho y la Salvatrucha se volvieron enemigas y tenían constantes enfrentamientos entre ellas y con las autoridades en las calles de Los Ángeles.

Con la Reforma de inmigración ilegal y responsabilidad migratoria, de 1996, el Congreso aprobó que los ciudadanos no estadounidenses condenados a más de un año de prisión fueran repatriados. Como resultado, 50.000 presos y 160.000 inmigrantes indocumentados fueron deportados a lo largo de la década siguiente (UNODC, 2007). Buena parte de ellos fue enviada a El Salvador, Guatemala y Honduras; los nicaragüenses emigraron, 
en la mayoría de casos, a Miami y Houston y, por contextos específicos locales, no participaron en dinámicas de pandillas de la misma magnitud; además, cerca de 180.000 inmigrantes ilegales nicaragüenses recibieron una amnistía en 1997 como "aliados en la lucha contra el comunismo" (Rocha, 2008b).

Al llegar a sus países de origen -que poco conocían-, reprodujeron con rapidez los comportamientos que les habían proporcionado apoyo y seguridad en Estados Unidos y establecieron "clicas" locales de la Dieciocho y la Salvatrucha. Las clicas lograron atraer a la juventud local y suplantaron o absorbieron a las pandillas locales. Aunque cada clica se relacionaba explícitamente con la Dieciocho o la Salvatrucha, ninguna de estas pandillas tenía una estructura federal y mucho menos transnacional, tampoco respondían a una cadena de mando única y su naturaleza "federada" era más un reflejo simbólico de su origen histórico que un demostrativo de unidad en acción o liderazgo (Ward, 2013).

Al mismo tiempo, esta trasposición transnacional de la cultura pandillera estadounidense en Centroamérica trajo consigo efectos devastadores, ya que era menos incrustada en el contexto institucional local y, por consiguiente, menos sujeta a reglas y restricciones. Por el contrario, esta trasposición respondió a dinámicas estadounidenses específicas que chocaban con los hábitos y patrones de comportamiento locales. Cabe señalar que el fenómeno de las maras no es tan solo un problema importado por deportados, sino uno que ha evolucionado y crecido en respuesta a factores y condiciones domésticas, que han llevado a que muchos de sus miembros ya no sean aquellos deportados (Demoscopía, 2007). Además, a diferencia de los numerosos reportajes sensacionalistas que relacionan a las pandillas centroamericanas con tráfico de migrantes, secuestros y crimen organizado internacional, los estudios existentes muestran que, en principio, estuvieron involucradas en operaciones locales de pequeña escala y con delincuencia común como hurtos y atracos que, con frecuencia, resultaban en homicidios.

Las maras en El Salvador, Guatemala y Honduras pronto se involucraron en extorsiones de negocios locales, buses y taxis dentro de los territorios bajo su control y existe evidencia de la participación de pandillas y maras en el tráfico y la distribución de drogas durante la última década y media. Esto no sorprende, si se considera que el consumo de drogas está bastante rela- 
cionado con su estilo de vida. Además, Centroamérica se ha transformado en el punto de tránsito para más de $80 \%$ del tráfico de cocaína entre los países andinos y Estados Unidos. ${ }^{7}$ Hasta hace poco, dicho tráfico en la zona era descentralizado, con cargamentos que pasaban de un pequeño cartel a otro - cada uno con una pequeña porción como ganancia-, mientras estos se desplazaban desde los carteles mucho más organizados de Colombia hacia los carteles de México. La función de las maras y pandillas consistía en prestar un servicio de seguridad local para estos pequeños carteles o vendedores callejeros conectados con ellas. Sin embargo, algunos estudios sugieren que sus líderes solían ser expandilleros que se habían "graduado", por así decirlo y que la última década mostraron una profesionalización significativa en el tráfico de drogas en la región.

Otro factor que influyó en la organización de estas pandillas -en particular, las maras de los países del triángulo norte- fue la introducción de políticas antipandillas, referidas como políticas de "mano dura" a principios de la década de 2000. Estas medidas produjeron confrontaciones de excesiva violencia entre pandillas y las autoridades en El Salvador, Honduras y Guatemala, cuyo resultado fue la profesionalización de pandillas, que adoptaron una imagen menos visible y también se involucraron más en el tráfico de drogas. En tiempos recientes, las maras declararon una tregua en El Salvador, lo que parece haber reducido la violencia, aunque no se ha comprobado la veracidad de este fenómeno. En Nicaragua, después de un primer intento de políticas de mano dura "suave", se ha logrado aislar a las pandillas por medio de una serie de transformaciones en infraestructura urbana, que busca su exclusión socioespacial a barrios pobres, para evitar el esparcimiento de la violencia de pandillas a barrios de clase más alta. La sostenibilidad de esta estrategia es bastante cuestionable, dado que este grado de aislamiento acarrea impactos en otras esferas de vida y se dificulta la participación en el mercado laboral.

Mucho se ha hablado de una presunta "corporatización" (Taylor, 1990, p. 9) de las pandillas de Centroamérica, como resultado del incremento del tráfico de drogas y como reacción a la represión estatal; algunos argumentan, de modo un poco determinista, que las pandillas han empezado 
a mutar en organizaciones criminales transnacionales (Sullivan, 2006). Esta realidad es mucho más compleja. Si bien es cierto que las políticas de mano dura han motivado a las pandillas a ser más organizadas y menos informales, la propagación de las drogas las ha llevado a competir con carteles de drogas y bandas criminales de carácter menos territorial. Estas organizaciones de mayor tamaño han venido absorbiendo a algunas pandillas $-\mathrm{O}$ a miembros individuales $-\mathrm{y}$ han ignorado o reprimido a las pandillas locales. Como resultado, mientras estos grupos persisten en Centroamérica, estudios recientes sugieren que están siendo "exprimidos" - desde un punto de vista sociológico- como actores significativos dentro de la economía política regional de violencia (Rodgers, 2012; Rodgers y Rocha, 2013). Es probable que esta sea una situación temporal, si nos basamos en el ciclo de violencia que ha afectado a la región durante los últimos veinticinco años.

\section{Pandillas en Brasil}

Tal vez más que cualquier otro país de América Latina, Brasil ha sido la cuna intelectual de estudios de la violencia urbana y la exclusión. En los últimos años, las pandillas se han convertido en tema de interés, no por ser un asunto reciente. Alba Zaluar $(1983 ; 1994)$ ya había cimentado las bases para la mayoría de investigaciones acerca de este fenómeno en ese país (Abramovay et al., 2002; Adorno et al., 1998; Arias, 2004; 2006; 2014; Barker, 2005; Dowdney, 2007; Gay, 2005; 2009; 2010; Goldstein, 2003; Leeds, 1996; Penglase, 2005; 2008; 2009; Perlman, 2010; Soares et al., 1996; Vianna, 1997). Gran parte de esta literatura tiende a enfocarse en las pandillas de Río de Janeiro, porque es un destino atractivo para investigadores internacionales y también porque es un centro internacional de respuestas gubernamentales y no gubernamentales hacia problemas de violencia de pandillas, canalizada por organizaciones como Viva Rio y Promundo. ${ }^{8}$ Sin embargo, existe una corriente emergente enfocada a explorar la violencia en otras ciudades como São Paulo (Denyer Willis, 2009; 2014; 2015; Holston, 2008), Fortaleza (Garmany, 2011) y Pernambuco

8 Para ampliar información, pueden verse http://www.vivario.org.br/en/ y http://www. promundo.org.br/en/ 
(Scheper- Hughes, 2015), aunque solo una pequeña porción está centrada en las pandillas.

Las pandillas cuentan con una larga historia en Brasil, remontada al siglo XIX, con la congregación de "maltas" en el puerto de Río de Janeiro (Soares, 2001), así como las "galeras cariocas" que tenían un carácter más musical y las "quadrilhas" de la década del setenta y del ochenta, de carácter más violento (Vianna, 1997). Desde principios de la década del noventa, esta escena ha sido dominada por pandillas traficantes más violentas, conocidas como "comandos". Su origen en Río de Janeiro empezó en la década del setenta, en la prisión Candido Mendes de Ilha Grande en el estado de Río, en donde criminales comunes se mezclaron con presos políticos con ideologías de izquierda arrestados por la dictadura militar y aprendieron tácticas y métodos de organización. Prisioneros sin afiliación política establecieron la Falange Vermelho, que luego se llamó Comando Vermelho, una vez retornaron a sus hogares en cerca de ochocientas favelas de Río de Janeiro. En sus años de formación, el Comando Vermelho estuvo dedicado, sobre todo, a "la ley y el orden" y brindaba protección y servicios de bienestar social para favelados, como financiamiento para guarderías infantiles y entregaba dinero a la población local para comprar gas de cocina (Penglase, 2008; Gay, 2009). Esto se estableció por medio de símbolos, discursos y tácticas, asociados con los principios de izquierda, que incluían proyectos normativos para la promoción de "boa vizinhança", lo que reflejaba la coletividade de la organización en la prisión (Penglase, 2008). Para cumplir esta función, el Comando Vermelho aprovechó la desconfianza generalizada que se tenía hacia la Policía y el abandono de las favelas por el Estado brasileño; por tanto, ganó espacio y arraigo en las comunidades.

En 1982, el Comando Vermelho tomó la decisión crucial de financiar sus actividades por medio del tráfico de drogas (Gay, 2009). Río de Janeiro es un punto clave en el transbordo de cocaína desde los países andinos hacia Europa, pero un $20 \%$ de estas drogas se vende en el país. La mayor parte de este comercio circula dentro de las favelas y es distribuido en las "bocas de fumo", es decir, esquinas dominadas por pandillas. La penetración de las drogas en las favelas de Río ha tenido un impacto profundo (Arias, 2006; Leeds, 1996). Perlman (2010) observa que el mayor cambio desde la década del setenta ha sido el dominio de las pandillas de drogas en muchas comunidades. Downey (2007) describe que el incremento de las pandillas 
en Río de Janeiro se divide en tres períodos: 1) la era precocaína, previa al Comando Vermelho; 2) la fase de dominio territorial y narcocultura por parte del Comando Vermelho en la década del ochenta y 3) la fase subsecuente a los 1990, caracterizada por disputas territoriales sangrientas, en las que varios líderes del Comando Vermelho - donos- fueron asesinados, puesto que crecían la desconfianza y la rivalidad. El tercer período también se destaca por la centralización del Comando Vermelho a finales de la década del noventa, lo que conllevó al declive de las raíces organizacionales de pandillas "respetuosas" de la "vieja guardia" que proveían servicios sociales (Penglase, 2008) y la aparición de una nueva variedad de pandillas rivales como el Terceiro Comando, el Comando Vermelho Jovem y los Amigos dos Amigos, que incrementaron las disputas territoriales por el control del mercado de drogas.

Este último hecho ha contribuido a una espiral de violencia relacionada con las pandillas de Río de Janeiro, demostrada al observar que la tasa de mortalidad por armas de fuego para la población de 15 a 24 años se ha triplicado - de 30 casos por cada 100.000 habitantes en 1980 a 103 en 2007- (Gay, 2009). Estas "guerras entre pandillas" produjo una brutal "guerra contra pandillas" por parte del Estado, lo que incrementó el derramamiento de sangre. El evento más notorio ocurrió en 2007, cuando 1.350 policías militares ingresaron a un grupo de favelas conocidas como el Complexo de Alemão para expulsar al Comando Vermelho y dejaron como resultado decenas de muertos (Gay, 2009; Gay, 2010; Leeds, 2007). La respuesta del Comando Vermelho llevó a la militarización de la favela y al uso de niños y jóvenes en el combate armado (Dowdney, 2003). Esto también alteró la dinámica ya compleja y ambigua entre las pandillas y la comunidad anfitriona. En los primeros años, las pandillas se entrelazaban con el tejido social de las comunidades locales (Leeds, 1996) y alrededor de ellas se creó un romanticismo místico tipo Robin Hood (Perlman, 2009). Sin embargo, una vez se involucraron en el tráfico de drogas, se transformaron en predadores locales despiadados (Perlman, 2009; 2010; Leeds, 1996). Las pandillas traficantes comenzaron a controlar asociaciones barriales y aquellos que demostraron desacuerdo fueron removidos forzosamente. Entre 1992 y 2002, cuatrocientos líderes comunitarios fueron asesinados y 450 desplazados, mientras muchos otros se alejaron de la vida pública (Gay, 2005; 2009). 
Esta escalada de violencia llevó a la implementación de uno de los ejemplos contemporáneos más conocidos en la prevención de la violencia y el crimen urbano, el Programa de Pacificación Urbana, el cual comenzó en 2008 e involucró el despliegue de unidades de policía pacificadoras (UPP), entrenadas para atender a las favelas afectadas por pandillas, en especial las más cercanas a las sedes de la Copa Mundial de Fútbol de 2014 y los Juegos Olímpicos de 2016 (Saborio, 2013). La UPP buscaba cumplir con operaciones diferentes a las realizadas a corto plazo por la Policía Militar. El programa opera en tres fases: 1) el Ejército y la Policía Militar -el Batalhão de Operações Policiais Especiais, BOPE- ocupan la favela (fase de intervención); 2) los oficiales de la UPP son introducidos (fase de estabilización) y 3 ) se establece el Estado, la infraestructura privada y los proyectos sociales (fase de consolidación). De esta forma, la UPP reclama su legitimidad y rompe los patrones ya existentes, al integrar iniciativas de seguridad y desarrollo (Jones y Rodgers, 2011). Se argumenta que, contrario a proyectos tales como "integrar Río" que buscan "normalizar" a la favela, la UPP permite a sus habitantes convertirse en ciudadanos de pleno derecho, y al Estado reclamar su soberanía sobre territorios en donde no tiene presencia (Muggah y Souza Mulli, 2012). Al hacerlo, también se puede argumentar que la pacificación vuelve a la favela un espacio más legible (Scott, 1998) y facilita el control por el Estado y la colonización por el sector privado. No obstante, existen críticas sobre la sostenibilidad del proyecto a largo plazo (Jones y Rodgers, 2015).

Las dinámicas de pandillas en São Paulo son comparables con las de Río. Mientras en las favelas de esta ciudad abundan las pandillas juveniles conocidas como "trombadinhas", dedicadas a crímenes menores, la pandilla principal de São Paulo recibe el nombre de Primeiro Comando da Capital (PCC). Del mismo modo que el Comando Vermelho, pero muchos años después, en 1993, surgió como una operación de pequeña escala en las prisiones de Carandiru y Taubaté y creció para volverse una institución omnipresente en los barrios pobres de la ciudad. El PCC no tiene origen político, como en el caso del Comando Vermelho, sino que es una respuesta colectiva a las condiciones y la violencia dentro de la prisión. Un incidente notable fue el asesinato de 111 reos en el centro de detención de Carandiru en 1991, que contribuyó a la creación de la PCC en la prisión de Taubaté dos años después (Denyer Willis, 2009). El PCC hizo una variedad de 
demandas dentro del marco de derechos humanos y estableció un sistema de control sobre el sistema de prisiones de São Paulo, que aportó una calma relativa a la vida de los reos. Holston (2008) ha argumentado que el PCC no es más que una "pandilla carcelaria", que ha usado el discurso de los derechos humanos como una cortina de humo para encubrir sus actividades criminales (Macaulay, 2007). Tras definir una red que abarcaba cientos de miembros en el sistema de prisiones de São Paulo, el PCC ganó apoyo en los barrios urbanos más pobres de la ciudad, ya que la mayoría de presos venían de estos lugares y era allí a donde retornaban. Esto permitió que el PCC obtuviera el control del tráfico de drogas hasta tal punto, que algunos académicos señalaron que el PCC constituyó una estructura paralela al Estado (Macaulay, 2007), aunque otros resaltan la relación simbiótica con elementos clientelistas de este (Denyer Willis, 2014; 2015).

\section{Pandillas en el resto de América Latina}

El resto de literatura académica acerca de pandillas en América Latina es mucho menos amplia y empíricamente detallada en comparación con la producida en Centroamérica y Brasil. Su mayor parte se basa en información suministrada por medios de comunicación y fuentes secundarias o en acercamientos indirectos al tema de las pandillas. Pese a que se han hecho estudios de investigación primaria en la mayoría de países latinoamericanos (Rodgers, 1999), estos suelen ser antiguos y desactualizados. Entre estos artículos encontramos a Lois B. DeFleur (1970), con su estudio de pandillas juveniles en Córdoba (Argentina) y Luis Salas (1979), con su trabajo de pandillas cubanas entre 1950 y 1960.

Estos artículos se ven limitados por cambios políticos, culturales, económicos y sociales que han afectado tanto a pandillas juveniles como a las sociedades en las que surgieron. Nuevos factores como el fin de la Guerra Fría, la globalización, la migración transnacional, la disminución del autoritarismo y el incremento de la clase media, entre otros, han contribuido a la transformación de América Latina durante la última mitad de siglo. Dicho esto, podemos destacar un grupo de estudios primarios interesantes enfocados en Colombia, Ecuador, México y Venezuela, que serán presentados a continuación. Como en los casos de Brasil y Centroamérica, las pandillas 
mencionadas en estos artículos abarcan desde las "clásicas" pandillas juveniles de esquina hasta grupos mucho más profesionales y organizados, en general involucrados en el tráfico de drogas. Cabe aclarar que la diferenciación entre estas suele ser bastante borrosa, debido a la evolución institucional y las políticas y prácticas clasificatorias.

\subsection{Colombia}

La mayoría de estudios en Colombia se centra en Medellín - la segunda ciudad más grande del país-, aunque también existen otros sobre la capital, Bogotá. También existe evidencia de la existencia de pandillas en ciudades de menor tamaño como Barranquilla, Neiva (Perea Restrepo, 2007), Cali, Cartagena y poblaciones fronterizas (Rodgers, 2003). El contexto de pandillas en Colombia está entrelazado con el marco de violencia política del cual ha sido víctima el país desde 1948, agravado por los efectos del tráfico de drogas desde la década del ochenta, en especial de cocaína y bazuco (una especie barata de crack) en los barrios pobres del casco urbano, en donde se encuentran las pandillas. En resumen, el conflicto armado, el auge del tráfico ilícito de drogas tanto local como internacional, la disponibilidad de armas pequeñas, la existencia de una cultura de brutalidad y una lógica de muerte (Perea Restrepo, 2007, p. 260) y el legado general del trauma (Riaño-Alcalá, 2006) se han combinado por los últimos setenta años, para crear un ambiente propicio para la violencia. Esta alcanzó su cenit durante la década del noventa, cuando los homicidios en Medellín registraron la tasa más alta de la historia de una ciudad, con 381 por cada 100.000 habitantes en 1991 (Suárez Rodríguez, 2005).

En este contexto, las pandillas y la violencia generada por estas en Colombia es bastante compleja (Rubio, 2007). Aunque se han establecido flujos y vínculos entre estas y el crimen organizado a lo largo de la región, las pandillas también han estado conectadas con grupos armados pertenecientes al conflicto político, en particular con guerrillas de izquierda y paramilitares de extrema derecha que incurren dentro de las ciudades del país. En este sentido, la violencia de pandillas quizás pueda entenderse mejor como parte de una clase de conflicto urbano de múltiples capas, algo que, como señalan Beall, Goodfellow y Rodgers (2013), es cada vez más frecuente en ciudades contemporáneas en vías de desarrollo. Estudios 
recientes realizados por Baird (2012a; 2012b) en Medellín y por Perea Restrepo en Bogotá (2007) han demostrado que los miembros de estos grupos rara vez se vinculan por motivos políticos revolucionarios, pese a que, en ocasiones, intenten influenciar decisiones políticas locales.

Las pandillas han existido en Medellín desde la década del cincuenta, pero eran relativamente benignas hasta el auge de la cocaína, en la década del ochenta, cuando se desencadenaron dos fenómenos: la venta local de bazuco y cocaína y el tráfico internacional que originó los infames carteles de drogas. Este período marcó el comienzo de una lucha criminal por el control del tráfico de drogas nacional e internacional que se originaba en Medellín, donde barones o capos, como Pablo Escobar, eran remplazados de manera constante. La figura del barón o capo comenzó a disminuir a finales de la década del noventa, con la emergencia de nuevas estrategias colaborativas entre la Policía Nacional y la Agencia para el Control de Drogas de Estados Unidos (DEA, por su nombre en inglés), lo que causó una reconfiguración en los carteles y propició el surgimiento de organizaciones criminales mucho más complejas. A principios del año 2000, paramilitares y neoparamilitares ${ }^{9}$ se vieron cada vez más involucrados en un ciclo sin fin de tráfico de drogas que hasta hoy no muestra señales de disminución (Aricapa, 2005; Baird, 2012b; Civico, 2012; Rozema, 2008).

A pesar de que los nexos entre pandillas y el crimen organizado han facilitado el flujo de armas, municiones y drogas, las pandillas callejeras no manejan un lucrativo comercio internacional de cocaína (Baird, 2012b; Civico, 2012; Rozema, 2008). Como ocurre en Río de Janeiro, este tipo de grupos depende del comercio local de drogas, extorsiones, lavado de activos y paga-diarios ${ }^{10}$ en sus barrios de acogida (Bedoya, 2010). Sus miembros emergen de la misma comunidad y se han arraigado en territorios determinados. Dado el contrastante índice de violencia al cual muchos jóvenes se han visto sometidos, estos reconfiguran su mundo subjetivamente. Riaño-Alcalá (2006) sostiene que los jóvenes utilizan historias de muerte

9 Los paramilitares son grupos de contrainsurgencia, enlistados por el Estado en Medellín para remover a la guerrilla. Estos paramilitares pronto se vieron involucrados en el tráfico de drogas, por lo que se complicó la diferenciación entre estos y los carteles de drogas. En algunos casos, este tipo de paramilitares reciben el nombre de neoparamilitares, después de un proceso limitado de desmovilización de los mismos en la década de 2000 (Baird, 2013; Civico, 2012).

10 "Paga-diarios" son préstamos a corto plazo con altísimos intereses. 
y narrativas de intimidación como estrategias de supervivencia para convivir en barrios violentos. Esto le ha dado forma "a las relaciones sociales e interpersonales, deteriorando las instituciones y valores establecidos en la sociedad, transformándose en la característica dominante de la sociedad colombiana" (Rodgers, 2003, p. 116).

Esto es algo que Perea Restrepo (2007) también ha comentado en su estudio acerca de pandillas en veintiún barrios pobres del sur de Bogotá. Este autor ve el hecho de pertenecer a una pandilla como un medio fluido de habitar la ciudad y navegar las relaciones complejas entre la violencia callejera y la violencia criminal (Perea Restrepo, 2007). Sin embargo, señala que, de los 1.000 grupos juveniles que estudió en esos barrios, solo un tercio podía considerarse como pandilla. En total, contó ochocientos miembros de pandillas entre 17.000 jóvenes entre 15 y 24 años que viven en estos barrios, lo que representa tan solo un $5 \%$ de la población juvenil (Perea Restrepo, 2007). El autor también afirma que existen varias palabras para referirse a las pandillas, como banda, parche, gallada o combo y pueden variar contextualmente. El término "banda" se utiliza para aquellos grupos del crimen organizado que operan fuera de la luz pública, mientras las pandillas son bastante visibles y hacen demostraciones públicas de poder. El "parche", que se refiere a un grupo de amigos, se utiliza con frecuencia para sugerir un grupo delincuente de los barrios pobres, lo que indica, en cierta forma, la manera en la que los jóvenes pobres son estigmatizados por su sociedad. No obstante, existen interconexiones fluidas entre el parche inocente, los miembros de pandillas y su "graduación" por las bandas.

\subsection{Ecuador}

Hasta hace poco no existían mayores estudios sobre las pandillas en Ecuador, pero durante la última década se ha evidenciado una proliferación de ellos (Carrión, 2002; Cerbino y Rodríguez, 2008; Santillán y Varea, 2008; Torres, 2006; Cerbino, 2011). Estos trabajos resaltan que las pandillas surgieron en Ecuador en la década del ochenta y están localizadas en Guayaquil y, en menor grado, en la capital Quito. Las pandillas ecuatorianas se dividen en "naciones" organizadas y pandillas menos organizadas, a menudo incorrectamente llamadas maras. Guayaquil cuenta con cerca de 1.200 pandillas, de las cuales cincuenta son naciones con un total de 
65.000 miembros, lo que representa un $7 \%$ de la población entre 12 y 20 años (Torres, 2006; Carrión, 2002; Santillán y Varea, 2008). Son de carácter territorial, ubicadas en barrios. La violencia entre ellas ha generado un incremento en la tasa de homicidios y una notoriedad mediática que las ha transformado en un asunto político desde principios del año 2000.

Los Latin Kings son la nación más grande de Ecuador y fueron creados por inmigrantes retornados de Estados Unidos a principios de la década del noventa. Esta pandilla está bastante organizada, con una estructura jerárquica y con jóvenes que pagan por su membresía; además, establecen celdas de presencia en diferentes barrios (Torres, 2006; Cerbino y Rodríguez, 2008; Santillán y Varea, 2008). Siguen reglas escritas en la "biblia" de los Latin Kings y cuentan con un repertorio cultural en el que la pandilla construye su organización o nación, "plantando una bandera" en el territorio de dominio (Cerbino y Rodríguez, 2008, p. 43). Cerbino y Rodríguez (2008) argumentan que esto diferencia a los Latin Kings de pandillas más orgánicas, en las cuales este fenómeno cultural nace como resultado de estructuras de exclusión. No existe claridad en cuanto al alcance de las naciones en temas de crimen organizado y tráfico de drogas y lo que puede ser entendido como sensacionalismo y estigmatización. Torres (2006) afirma que los Latin Kings de Guayaquil son la nación más violenta en términos de homicidios. En cambio, en 2007, a los Latin Kings de Quito se les otorgó estatus legal -un acto simbólico y jurídico-, con el fin de transformar esta pandilla en una organización social que incluso llegó a recibir el apoyo del presidente Rafael Correa (Carrión, 2006).

\subsection{México}

Como lo resalta la película Los Olvidados, de Luis Buñuel, realizada en 1950, las pandillas no son un fenómeno nuevo en la sociedad mexicana. Esto se evidencia también en los estudios sobre barrios pobres de invasión urbanos durante las décadas del cincuenta y del sesenta (Lewis, 1961), en donde las pandillas surgen como un vehículo orgánico para interactuar entre jóvenes y hacer actividades de adolescentes. El estudio clásico de Rossana Reguillo (1991) sobre las pandillas callejeras en Guadalajara destaca que esta lógica comienza a cambiar en la década del ochenta y muestra que estos grupos -conocidos como bandas- empiezan a preocuparse por la 
provisión de puntos de referencia culturales y un sentido de pertenencia en un contexto en donde las instituciones tradicionales como la familia, el trabajo, la escuela y la Iglesia estaban debilitándose, debido a transformaciones estructurales de mayor escala, en particular a la liberalización económica. La autora describe a las pandillas como una nueva expresión de cultura juvenil, adaptada a un nuevo contexto. Este tema ha persistido en estudios contemporáneos, con bastantes investigaciones enfocadas en identidades sociales y prácticas cotidianas dentro de las pandillas (Castillo Berthier, 2002; 2004; Castillo Berthier y Jones, 2009; Cruz Salazar, 2004; Gigengack, 2006; Herrera et al., 2009), aunque se debe resaltar un creciente cambio de énfasis hacia la forma como la experiencia de pandilla mexicana refleja cada vez más un contacto cultural con la juventud estadounidense, sea al involucrarse con pandillas como migrante o al conocer a alguien que ha emigrado (Hernández León, 1999; Nateras Domínguez, 2006; 2007). Ciertos trabajos se han centrado en otras ciudades fronterizas como Nogales y discuten la cultura de pandilla juvenil marginalizada e híbrida que ha surgido en esa ciudad (Rosas, 2012).

Las pandillas mexicanas también se han convertido en un reciente punto de interés en relación con el incremento de violencia asociada con organizaciones involucradas en el tráfico de drogas desde los principios del año 2000. Como lo señala Nathan Jones (2013):

[...] mucho se ha dicho en cuanto a la alianza potencial entre pandillas y carteles [...] aunque las pandillas y los carteles suelen tener miembros en común, la mayoría de pandillas mexicanas no cuentan con conexiones transnacionales o conexiones con organizaciones involucradas en el tráfico de drogas significativas (p. 8).

Este autor cita informes de los medios de comunicación para argumentar que, en 2009, existían más de 1.600 pandillas juveniles en Monterrey, pero solo se había comprobado la participación de veinte de ellas en el tráfico de drogas. Sugiere que el vínculo entre las pandillas y las drogas se debe, sobre todo, al alarmismo mediático, mas reconoce que esto puede suceder por la forma en la que las maras centroamericanas han invadido el sur de México. El problema, dice Gareth A. Jones (2014), es que el involucramiento de las pandillas en el discurso de seguridad pública significa que 
estas se construyen de manera particular. Más preocupante aún es que a la categoría de "joven" se le atribuye cada vez más un sentido de "pandillero", por lo que se producen políticas y prácticas de gobernabilidad particulares, que estigmatizan a la juventud en general.

\subsection{Venezuela}

A pesar de que Venezuela sobresale cada vez más como un país violento emergente, con cifras de homicidios en constante aumento desde 1995 que alcanzan una tasa de 54 por cada 100.000 personas en 2012 (UNODC, 2014), existen insuficientes estudios acerca de pandillas en este país. Aunque se ha demostrado que esta violencia es de carácter armado, urbano, social y, de acuerdo con las pocas investigaciones primarias, está relacionada con pandillas (Zubillaga, 2007; 2009; 2013; Antillano y Zubillaga, 2013). Hasta cierto punto, ello se debe a que las pandillas solo han sido resaltadas recientemente en el panorama de violencia y también a que son pequeños grupos desorganizados locales, sin una génesis política o histórica relevante. Carecen de la organización de las naciones en Ecuador, los comandos en Brasil o las maras en Centroamérica y no tienen el mismo tipo de conexiones con el crimen organizado que las pandillas de Colombia. No obstante, estudios recientes han mostrado que las actividades del Estado venezolano crean un "estado de guerra", al promover la estigmatización letal de jóvenes de piel oscura con ingresos bajos (Zubillaga et al., 2015).

Las investigaciones acerca de las pandillas en Venezuela se orientan, casi en su totalidad, en Caracas (Pedrazzini y Sánchez, 1992; Zubillaga, 2009; Antillano y Zubillaga 2013), porque, en cierto modo, las pandillas tomaron fuerza con el levantamiento violento denominado Caracazo, ocurrido en los barrios pobres de Caracas en 1989, cuando los habitantes saquearon las tiendas en protesta contra las nuevas políticas económicas neoliberales del Gobierno. Mateo y González (1998) observan que la violencia de pandillas durante este período sobresalió, puesto que fue "exagerada" (p. 230). No cabe duda de que las pandillas -conocidas como "bandas" y sus integrantes, como "malandros" - surgieron como una subcultura particular que predicaba "la rebelión y no la revolución", a las que los jóvenes marginados no se unían para cambiar el sistema, sino para protegerse de la violencia y la incertidumbre. En este caso las pandillas tienden a actuar para proteger su 
territorio de otras pandillas y mantener "la ley y el orden", con la ejecución de ladrones conocidos (Zubillaga, 2007, p. 594). Es alarmante que, en los últimos años, la violencia de pandillas en Caracas se hubiera incrementado, a pesar de programas para reducir la pobreza como Barrio Dentro, que empezaron en el gobierno del presidente Hugo Chávez, lo que nos lleva a la paradoja de "menos desigualdad, más violencia" (Zubillaga, 2013, p. 104).

\section{Temáticas clásicas sobre las pandillas en América Latina}

\subsection{Lazo social}

Un aspecto recurrente en estudios sobre pandillas latinoamericanas es su origen dentro de contextos sociales particulares. Contrario a la interpretación predominante en la literatura estadounidense sobre la relación histórica entre las pandillas y sus contextos - que asume a las primeras como resultado del caos y de la "desorganización social" de los segundos-, los estudios en América Latina han demostrado una y otra vez que los lazos sociales entre las pandillas y su comunidad suelen ser fuertes y organizados, aunque no necesariamente con resultados sociales y políticos positivos. Zaluar $(1997 ; 2000)$ ha expuesto que la formación de pandillas en Río de Janeiro dio lugar a una forma de "integración perversa" de las favelas dentro del cuerpo político brasileño y creó una distancia, pero otros estudios han revelado que comunidades pobres y marginadas pueden relacionarse de manera más positiva con las pandillas y su violencia cuando estas brindan cierto orden, por ejemplo, "protección" funcional de la comunidad ante incursiones de pandillas externas (Rodgers, 2006a; Zubillaga, 2007). En algunos casos, este vínculo puede ser aún más complejo, como lo destacan Arias y Davis Rodrigues (2006) en su trabajo sobre pandillas en Río de Janeiro, en el cual afirman que las pandillas pueden construir su reputación y extender su dominio por medio de formas de control territorial y también de la imposición de normas ligadas con el manejo de la violencia doméstica, el abuso infantil, el alcoholismo, el abuso de drogas y las disputas patrimoniales. Al mismo tiempo, otras investigaciones sugieren que la relación entre pandillas y sus comunidades es muy volátil (Rodgers, 2007b). 


\subsection{Vacíos gubernamentales y poderes paralelos}

El histórico abandono de las comunidades pobres de América Latina (O'Donnell, 1993) es una de las razones por las que las pandillas aparecen como proveedores alternativos de seguridad y remplazan a instituciones ausentes como la Policía. Así, la desidia del Estado deja "vacíos gubernamentales" (Kruijt y Koonings, 1999) suplidos por ellas. Por eso, el incremento de las pandillas como una forma localizada de "poder soberano" en la periferia de muchas ciudades en América Latina ha propiciado debates en torno a si las pandillas constituyen o no un "poder paralelo" al Estado. Respecto a Cochabamba (Bolivia) y Río de Janeiro, Goldstein (2003) afirma que, en la ausencia del Estado, "las pandillas proveen un sistema de justicia alternativo -o un Estado paralelo- entre los pobres" (p. 207). Por otro lado, Arias (2006) comenta que los imperios de drogas que manejan las pandillas no son necesariamente construidos debido a la ausencia del Estado, sino en coalición con elementos corruptos de este y con políticos que permiten a las pandillas "un nivel de poder localizado para rechazar agentes del Estado que intenten reprimir el crimen" (p. 2). En Medellín, las pandillas eran controladas por grupos paramilitares relacionados con el Estado a principios de la década de 2000, en donde el rol de las primeras fue asociado con un proyecto estatal más amplio y perverso (Noche y Niebla, 2002; Baird, 2013). Asimismo, Perlman (2009) manifiesta que aunque las pandillas remplazan un vacío provocado por la ausencia del Estado si no proveen bienestar y servicios sociales. En parte debido a estas ambigüedades, el surgimiento de las pandillas ha impulsado debates sobre la naturaleza de la democracia contemporánea en América Latina en el período posterior a la Guerra Fría. Algunos cuestionan si ha emergido en la región una nueva forma de gobierno democrático parcial, con normativas que involucran formas limitadas de violencia (Arias y Goldstein, 2010), mientras otros argumentan que la violencia siempre ha existido y es parte de la gobernabilidad en América Latina (Rodgers, 2006b).

\subsection{Machismo/género}

Debido a que la mayoría de los miembros de pandillas en América Latina son hombres jóvenes, no sorprende que varios académicos las relacionaran con machismo y construcción de la identidad masculina o 
masculinidades (Barker, 2005; Baird, 2012b; Zubillaga, 2009; Zubillaga y Briceño-León, 2001). Estos estudios analizan las razones por las cuales los jóvenes se unen a las pandillas, enfocados en la identidad masculina y la lucha por el estatus y la estima en un contexto más amplio de exclusión social penetrante. En estos espacios, las pandillas se convierten en mecanismos de atracción para jóvenes pobres que buscan alcanzar una "hombria", para convertirse en imaginarios de admiración. Las identidades masculinas se manifiestan tanto en la violencia de hombre a hombre como de hombre a mujer, incluidas las golpizas y violaciones grupales para iniciar a miembros femeninos en Centroamérica (Hume, 2004; Aguilar Umaña y Rikkers, 2012). La representación de miembros femeninos tiende a resaltar su estatus como objetos sexuales (Hopper y Moore, 1990; Baird, 2015), aunque Gay (2005) muestra una imagen diferente. En América Latina existen pocas mujeres pandilleras en posiciones de poder $\mathrm{y}$, en general, son pocas las mujeres que pertenecen a pandillas, pero su presencia se observa en Guatemala, Nicaragua y México (Cummings, 1994; Rodgers, 2006a; Winton, 2007). Hacia el futuro, se observa una necesidad clara de investigar las interacciones entre mujeres y niñas con la vida pandillera, la construcción de masculinidades dentro de espacios de socialización de la pandilla y las interconexiones entre género, clase, raza y violencia de pandillas (Baird, 2015; Hume y Wilding, 2015).

\section{Temas emergentes sobre pandillas latinoamericanas}

\subsection{Evolución de pandillas}

Un gran vacío en la literatura sobre pandillas latinoamericanas es la ausencia de estudios longitudinales, pues la mayoría presenta a las pandillas en un momento específico. Esto puede atribuirse a las dificultades metodológicas que acarrea una investigación primaria sobre el tema (Baird, 2009; Rodgers, 2007a), lo cual significa que muchos trabajos acerca de pandillas surgen de manera fortuita o son resultado indirecto de otras investigaciones y se complica su replicación. Además, los estudios longitudinales de la vida en las comunas populares o barrios pobres de invasión urbanos son escasos (Moser, 2009; Perlman, 2010), así como aquellos sobre la evolu- 
ción de pandillas; se destacan las indagaciones de Dennis Rodgers y José Luis Rocha, en particular su trabajo conjunto de 2013 sobre pandillas en Nicaragua, único en este aspecto. Esto significa que entendemos mucho menos sobre las pandillas en América Latina de lo que deberíamos (Ayling, 2011; Densley, 2014).

Se ha demostrado que la penetración de las drogas en barrios marginales tiene efectos transformadores en las pandillas y provocan mayores flujos económicos, guerras de territorios por el control de venta de drogas y fortalecimiento de lazos entre el crimen organizado y la distribución ilegal de armas (Rodgers, 2013). En muchos casos, dicha incursión de las drogas altera cualquier actividad $\mathrm{u}$ objetivo inicial de servir a la comunidad y genera formas depredadoras de interacción con las comunidades de acogida (Rodgers, 2006a; 2007b). Esto también es ejemplificado por Perlman (2009), quien concluye, después de años de permanencia en favelas, que a pesar de que en principio las pandillas pueden ser garantes de códigos normativos para la cohesión social, las que están involucradas en el tráfico de drogas terminan por "no reconocer responsabilidad alguna hacia el bienestar de la población" (p. 63).

\subsection{Transnacionalismo}

El movimiento real y percibido de pandillas en las fronteras ha motivado a un discurso cada vez mayor acerca de "pandillas transnacionales" (Sullivan y Elkus, 2009; Cerbino y Barrios, 2008). Desde hace poco, la discusión se ha centrado en las maras de Centroamérica, las cuales son representadas como "superpandillas" transnacionales - se reporta la existencia de dos grupos: la mara Dieciocho y la mara Salvatrucha, también conocidas respectivamente como M-18 y MS-13- que operan a lo largo del istmo centroamericano y en amplias franjas de Estados Unidos y Canadá. Reportes policiales han señalado, en numerosas ocasiones, la supuesta existencia de lazos entre las maras provenientes de Estados Unidos y El Salvador. En 2004, el FBI creó una fuerza especial dedicada a las maras y, en 2005, abrió una oficina especial en San Salvador para monitorear una posible amenaza transnacional. Los estudios académicos acerca de las maras enfatizan que estas son un fenómeno social local y resaltan que, aunque diferentes pandillas locales se identifican con la mara Dieciocho y la mara 
Salvatrucha, ninguna de estas "supermaras" tiene una estructura federal y mucho menos transnacional. A lo mejor, su naturaleza federal es un imaginario simbólico de su origen histórico, en vez de una verdadera unidad o un liderazgo centralizado auténtico (Jütersonke, Muggah y Rodgers, 2009).

No cabe duda de que los pandilleros sí migran -sería sorpresivo que no lo hicieran, si se considera el porcentaje de la población latinoamericana que está en movimiento-y, más allá de las maras, Cerbino y Barrios (2008) y Queirolo Palas (2009) han reflexionado sobre el transnacionalismo de los Latin Kings, los cuales se expandieron de Estados Unidos a Ecuador a principios de la década del noventa y siguieron de Ecuador a España, Italia, Alemania y Bélgica a finales de ese período (Cerbino y Barrios, 2008). Podría decirse que la existencia de los Latin Kings en España surgió por la influencia cultural transnacional de esta pandilla o como consecuencia de una generación de migrantes económicos que siguieron a sus padres a ese país. Lo anterior nos invita a reflexionar si las "pandillas transnacionales" deberían ser entendidas como un fenómeno político y cultural globalizado, una expresión de organizaciones juveniles en contextos de exclusión persistente o como una consecuencia lógica del movimiento de diásporas que se desplazan entre sus países de origen y de residencia. Un enfoque más reciente se ha centrado en ciudades fronterizas como Nogales, ubicado en el límite que divide a Arizona (Estados Unidos) y Sonora (México), en particular en las culturas de pandillas hîbridas que surgen entre estos espacios liminales (Rosas, 2012).

\subsection{La economía política de las políticas públicas}

Las políticas públicas relacionadas por las pandillas suelen ser controversiales. Por ejemplo, las infames políticas de Mano Dura, introducidas en Centroamérica a mediados de la década de 2000 han sido criticadas por aumentar la violencia (Aguilar, 2006) y denunciadas como reflejo de la naturaleza oligarca de la sociedad regional (Rodgers y Muggah, 2009). Esta es una de las pocas políticas de pandillas que ha estado bajo escrutinio, pero hay un gran espectro de estas que podrían ser examinadas más a fondo. Entre ellas se destaca la noción de Policía Comunitaria, tan popular en la década del noventa, pero que carece de evidencia clara de respaldo. 
Otro mirada posible es la importancia de la retórica política por encima de la realidad empírica, como lo demuestra el paradigma de seguridad ciudadana, surgido en América Latina en el período posdictadura, subsecuente a la Guerra Fría, cuando se redefinió el concepto de la seguridad, alejado de las amenazas que afectan al Estado y se acercó a las inseguridades individuales que inciden en los derechos y la ciudadanía (Adams, 2012; Costa, 2012; Rodgers y Muggah, 2009; UNDP, 2013). Por un lado, el incremento de seguridad ciudadana refleja el cambio de retos que afronta la zona, con una violencia que no corresponde a la guerra tradicional, sino criminal y social dentro de un contexto democrático. Por otro, también forma parte del legado de políticas que han venido evolucionado en respuesta a imperativos políticos y económicos y no responden necesariamente a realidades empíricas que se pueden comprobar.

La violencia de las pandillas se ha convertido en punto focal para políticas de seguridad ciudadana. Han surgido tres enfoques particulares que reflejan la visión de este discurso: a) represión y medidas punitivas, que involucran encarcelamiento y trabajo policial; b) intervenciones como la negociación y desmovilización de pandillas, y c) prevención para disminuir la vinculación a pandillas y el uso de violencia en estas (Small Arms Survey, 2010). Las medidas represivas todavía presentan una respuesta sensacionalista, populista y politizada a la violencia de pandillas a lo largo de la región, a pesar de las lecciones aprendidas sobre las limitaciones de políticas de Mano Dura empleadas en el pasado. Sin embargo, la presión de reducir los índices de homicidio, combinados con el fracaso de Mano Dura, ha llevado a experimentar con técnicas de negociación y desmovilización como en el caso de Medellín o San Salvador. Cabe aclarar que las negociaciones con pandillas suelen ser inestables y sus impactos duraderos son bastante cuestionados. Por fin, otro tema que se debe explorar con más detalle, en relación con las políticas públicas, es el hecho de que el indicador de violencia que más sobresale en comparaciones sobre temas de seguridad es la tasa de homicidio (UNODC, 2014). Este indicador es tan solo un barómetro parcial de sociedades violentas, "acomodado" o alterado por las autoridades (Rodgers y Rocha, 2013) y, por eso, no es la mejor manera de representar la violencia. 


\section{Conclusión: una agenda para futuros estudios}

Aunque existen buenas fuentes de conocimiento sobre las pandillas en América Latina, la información todavía no es robusta, debido a sus vacíos geográficos, tanto de países como de ubicación espacial. Muestra de ello es la falta de estudios sustanciales sobre pandillas en Paraguay y Uruguay, pese a que los medios de comunicación afirman su existencia en ambas sociedades. También sorprende que buena parte de los estudios primarios sobre pandillas haya ocurrido en ciudades grandes, cuando ha existido un incremento significativo en ciudades pequeñas y medianas durante las últimas dos décadas. Es claro que existe una necesidad de más estudios en la región que profundicen más allá de las opciones obvias de Medellín, Río de Janeiro, Tegucigalpa o San Salvador.

Otro aspecto concerniente al estado de los estudios de pandillas en América Latina es que numerosos estudios tienden a enfocarse tan solo en una pandilla o un grupo que opera en una comunidad determinada, pero rara vez se considera la relación contextual intercultural. Muchos factores causales de violencia pandillera son compartidos en varias ciudades, aunque con diferencias locales y problemáticas específicas. Por consiguiente, existe la clara necesidad de desarrollar estudios comparativos, debido al carácter transnacional de algunas pandillas y a la forma en que las comparaciones revelan supuestos, límites y distinciones de argumentos empíricos y teóricos que permiten formular nuevas líneas de investigación (Hazen y Rodgers, 2014). De forma similar, existe la necesidad de incrementar el número de investigaciones longitudinales para poder apreciar la evolución de las pandillas.

Si bien los investigadores visitan comunidades con una presencia significativa de pandillas, la cantidad de información empírica proveniente de los mismos miembros de ellas es bastante limitada. Hasta cierto punto, esto ocurre por razones prácticas, pero existen ejemplos - en América Latina y en otros sitios- de estudios que interactúan con miembros de pandillas y no es accidental que este tipo de estudios suele ser más reveladores. Eso permitiría entender por qué solo una minoría de la juventud se une a las pandillas, incluso en barrios saturados de estas. Esto es algo que los estudios latinoamericanos rara vez consideran, aunque su investigación podría contribuir a la prevención de la membresía y violencia de pandillas. 
Estas nuevas líneas de búsqueda requieren nuevos métodos investigativos y colaborativos entre investigadores - gran parte de los estudios de pandillas se han hecho de manera individual-y también con miembros de pandillas. Los últimos años han visto un incremento en la creación de ONG como Homies Unidos en El Salvador, que han empezado a crear conexiones entre investigadores y miembros de pandillas activos y retirados. Sin embargo, estas conexiones no van más allá de una relación desigual de recolector de información e informante. Se podría pensar en maneras de promover un trabajo verdaderamente colaborativo entre investigadores y pandilleros que combine sus conocimientos. En general, los trabajos sobre pandillas apuntan a promover perspectivas y políticas particulares, en vez de ofrecer una mirada balanceada a lo que ya es una situación trágica. Esto es cierto en cuanto a la controversial "securitización" de políticas de desarrollo tanto en América Latina como en el resto del mundo (Jones y Rodgers, 2015), así como otras formas de estigmatización y el sensacionalismo de la prensa que previenen el afrontamiento coherente al problema social real que representan las pandillas para América Latina.

\section{Referencias}

Abramovay, M., Waiselfisz, J. J., Andrade, C. C. y das Graças Rua, M. (2002). Guangues, galeras, chegados e rappers: Juventude, violência e cidadania nas cidades da periferia de Brasilia. Río de Janeiro: Garamond.

Adams, T. M. (2012). Chronic Violence and Its Reproduction: Perverse Trends in Social Relations, Citizenship, and Democracy in Latin America. Washington: Woodrow Wilson International Centre for Scholars.

Adorno, S., De Lima, R. S., Feiguin, D., Biderman, F. y Bordini, E. (1998). O adolescente e a criminalidade urbana em São Paulo. Revista Brasileira de Ciencias Criminais, 6, 189-204.

Aguilar, J. (2006). Los efectos contraproducentes de los planes Mano Dura. Quorum, 16, 81-94.

Aguilar Umaña, I. y Rikkers, J. (2012). Violent Women and Violence Against Women: Gender Relations in the Maras and Other Street Gangs of Central America's Northern Triangle Region. Bruselas: Initiative for Peacebuilding and Interpeace.

Antillano, A. y Zubillaga, V. (2013). La conexión drogas ilícitas violencia: una revisión de la literatura y consideraciones a la luz de la experiencia venezolana. Espacio Abierto: Cuaderno Venezolano de Sociología, 23(1), 129-148. 
Arias, E. D. (2004). Faith in Our Neighbors: Networks and Social Order in Three Brazilian Favelas. Latin American Politics and Society, 46(1), 1-38.

Arias, E. D. (2006). Drugs and Democracy in Rio de Janeiro: Trafficking, Social Networks and Public Security. Chapel Hill: University of North Carolina Press.

Arias, E. D. (2014). Gang Politics in Rio de Janeiro, Brazil. En J. M. Hazen y D. Rodgers (eds.), Global Gangs: Street Violence across the World (pp. 237-254). Mineápolis: University of Minnesota Press.

Arias, E. D. y Davis Rodrigues, C. (2006). The Myth of Personal Security: Criminal Gangs, Dispute Resolution, and Identity in Rio de Janeiro's Favelas. Latin American Politics and Society, 48(4), 53-81.

Arias, E. D. y Goldstein, D. M. (eds.). (2010). Violent Democracies in Latin America. Durham: Duke University Press.

Aricapa, R. (2005). Comuna 13: crónica de una guerra urbana. Medellín: Universidad de Antioquia.

Ayling, J. (2011). Gang Change and Evolutionary Theory. Crime, Law and Social Change, 56(1), 1-26.

Baird, A. (2009). Methodological Dilemmas: Researching Violent Young Men in Medellín, Colombia. IDS Bulletin, 40, 72-77.

Baird, A. (2012a). Negotiating Pathways to Manhood: Rejecting Gangs and Violence in Medellin's Periphery. Journal of Conflictology, 3(1), 30-41.

Baird, A. (2012b). The Violent Gang and the Construction of Masculinity Amongst Socially Excluded Young Men. Safer Communities: A Journal of Practice, Opinion, Policy and Research, 11(4), 179-190.

Baird, A. (2013). ¿Héroes olvidados? Activismo de la sociedad civil y las políticas de juventud en Medellín. En A. Baird y F. Serrano (eds.), Paz paso a paso: una mirada desde los estudios de paz a los conflictos colombianos (pp. 29-52). Bogotá: Pontificia Universidad Javeriana.

Baird, A. (2015a). Swimming Against the Tide: Youth Policy and Contexts of Chronic Violence in Medellín. En P. Filzmaier, P. Plaikner, C. Hainzl, D. Ingruber y K. A. Duffek (eds.), Jugend und Politik (pp. 77-91). Viena: Facultas-Verlag.

Baird, A. (2015b). Duros and Gangland Girlfriends: Male Identity and Gang Socialisation in Medellín. En J. Auyero, P. Bourgois y N. Scheper-Hughes (eds.), Violence at the Urban Margins (pp. 112-133). Oxford: Oxford University Press.

Barker, G. (2005). Dying to be Men: Youth, Masculinity and Social Exclusion. Londres: Routledge.

Beall, J., Goodfellow, T. y Rodgers, D. (2013). Cities and Conflict in Fragile States in the Developing World. Urban Studies, 50(15), 3065-3083. 
Bedoya, J. (2010). La protección violenta en Colombia: el caso de Medellín desde los años noventa. Medellín: Instituto Popular de Capacitación.

Bolognesi, P. (2009). Il recupero dei pandilleros da parte di una chiesa evangelica pentecostale a Managua, Nicaragua. (Tesis doctoral inédita). Universidad de Bologna, Italia.

Brenneman, R. (2012). Homies and Hermanos: God and Gangs in Central America. Oxford: Oxford University Press.

Bruneau, T., Dammert, L. y Skinner, E. (eds.). (2011). Maras: Gang Violence and Security in Central America. Austin: University of Texas Press.

Carrión, F. (2002). De la violencia urbana a la convivencia ciudadana. En F. Carrión (ed.), Seguridad ciudadana: ¿espejismo o realidad? (pp. 13-58). Quito: Flacso, OMS, OPS.

Castillo Berthier, H. (2002). De las bandas a las tribus urbanas. Desacatos, 9, 57-71.

Castillo Berthier, H. (2004). Pandillas, jóvenes y violencia. Desacatos, 14, 105-126.

Castillo Berthier, H. y Jones, G. A. (2009). Mean Streets: Gangs, Violence and Daily Life in Mexico. En G. A. Jones y D. Rodgers (eds.), Youth Violence in Latin America: Gangs and Juvenile Justice in Perspective. Nueva York: Palgrave.

Castro, M. y Carranza, M. (2001). Las maras en Honduras. En ERIC, Ideso, Idies e ludop (eds.), Maras y pandillas en Centroamérica (Vol. 1) (pp. 218-332). Managua: UCA Publicaciones.

Cerbino, M. (2012). El lugar de la violencia: perspectivas críticas sobre pandillerismo juvenil. Quito: Flacso, Santillana, Taurus.

Cerbino, M. y Barrios, L. (ed.). (2008). Otras Naciones: jóvenes, transnacionalismo y exclusión. Quito: Flacso.

Cerbino, M. y Rodríguez, A. (2008). La Nación imaginada de los Latin Kings: criminología cultural y la banda transnacional. En M. Cerbino y L. Barrios (eds.), Otras Naciones: jóvenes, transnacionalismo y exclusión. Quito: Flacso.

Civico, A. (2012). We are Illegal, but not Illegitimate: Modes of Policing in Mede1lin, Colombia. PoLAR: Political and Legal Anthropology Review, 35(1), 77-93.

Costa, G. (2012). Citizen Security in Latin America. Recuperado de http://m.thedialogue.org/PublicationFiles/GinoCostaEnglishFINAL.PDF

Cruz, J. M. (2005). Los factores asociados a las pandillas juveniles en Centroamérica. Estudios Centroamericanos, (685-686), 1155-1182.

Cruz, J. M. (2010). Central American Maras: From Street Youth Gangs to Transnational Protection Rackets. Global Crime, 11(4), 279-298.

Cruz, J. M. (2014). Maras and the Politics of Violence in El Salvador. En J. M. Hazen y D. Rodgers (eds.), Global Gangs: Street Violence across the World. Mineápolis: University of Minnesota Press. 
Cruz, J. M. y Portillo Peña, N. (1998). Solidaridad y violencia en las pandillas del gran San Salvador: más allá de la vida loca. San Salvador: UCA Editores.

Cruz Salazar, T. (2004). Yo me aventé como tres años haciendo tags, isí, la verdad, sí fui ilegal! Grafiteros: arte callejero en la ciudad de México. Desacatos, 14, 197-226.

Cummings, L. L. (1994). Fighting by the Rules: Women Street-Fighting in Chihuahua, Chihuahua, Mexico. Sex Roles, 30(3-4), 189-198.

DeCesare, D. (1998). The Children of War: Street Gangs in El Salvador. NACLA: Report on the Americas, 32(1), 21-29.

DeCesare, D. (2013). Unsettled/desasosiego: los niños en un mundo de las pandillas. Austin: University of Texas Press.

DeFleur, L. B. (1970). Delinquency in Argentina: A Study of Córdoba's Youth. Pullman: Washington State University.

Demoscopía, S. A. (2007). Maras y pandillas, comunidad y policía en Centroamérica. San José: Autor.

Densley, J. A. (2014). It's Gang Life, but not as We Know It: The Evolution of Gang Business. Crime \& Delinquency, 60(4), 517-546.

Denyer Willis, G. (2009). Deadly Symbiosis? The PCC, the State and the Institutionalization of Violence in São Paulo. En G. A. Jones y D. Rodgers (eds.), Youth Violence in Latin America: Gangs and Juvenile Justice in Perspective. Nueva York: Palgrave.

Denyer Willis, G. (2014). Antagonistic Authorities and the Civil Police in São Paulo, Brazil. Latin American Research Review, 49(1), 3-22.

Denyer Willis, G. (2015). The Killing Consensus: Police, Organized Crime and the Regulation of Life and Death in Urban Brazil. Berkeley: University of California Press.

Dowdney, L. (2003). Children of the Drug Trade: A Case Study of Children in Organised Armed Violence in Rio de Janeiro. Río de Janeiro: 7 Letras.

Dowdney, L. (2007). Neither War nor Peace: International Comparisons of Children and Youth in Organised Armed Violence. Río de Janeiro: Viva Rio, COAV, Iansa. ERIC, Ideso, Idies e Iudop. (2001). Maras y pandillas en Centroamérica (Vol. 1). Managua: UCA Publicaciones.

ERIC, Ideso, Idies e Iudop. (2004). Maras y pandillas en Centroamérica: pandillas y capital social (Vol. 2). San Salvador: UCA Publicaciones.

ERIC, Ideso, Iudop, Nitlapan y Dirinpro. (2004). Maras y pandillas en Centroamérica: políticas juveniles y rehabilitación (Vol. 3). Managua: UCA Publicaciones.

Garmany, J. (2011). Drugs, Violence, Fear, and Death: The Necro and Narco-Geographies of Contemporary Urban Space. Urban Geography, 32(8), 1148-1166. 
Gay, R. (2005). Lucia: Testimonies of a Brazilian drug dealer's woman. Filadelfia: Temple University Press.

Gay, R. (2009). From Popular Movement to Drug Gangs to Militias: An Anatomy of Violence in Rio de Janeiro. En K. Koonings y D. Kruijt (eds.), Mega-Cities: The Politics of Urban Exclusion and Violence in the Global South (pp. 29-51). Londres: Zed Books.

Gay, R. (2010). Toward Uncivil Society: Causes and Consequences of Violence in Rio de Janeiro. En E. D. Arias y D. M. Goldstein (eds.), Violent Democracies in Latin America (pp. 202-225). Durham: Duke University Press.

Gigengack, R. (2006). Young, Damned and Banda: The World of Young Street People in Mexico City, 1990-1997. (Tesis doctoral inédita). School for Social Science Research, University of Amsterdam, Holanda.

Goldstein, D. (2003). Laughter Out of Place: Race, Class, Violence and Sexuality in a Rio Shantytown. Berkeley: University of California Press.

Grassi, P. (2011). La zona roja: potere ed utilizzo del territorio urbano a città del Guatemala. Confluenze, 3(2), 181-196.

Gutiérrez Rivera, L. (2010). Discipline and Punish? Youth Gangs' Response to "Zero-Tolerance" Policies in Honduras. Bulletin of Latin American Research, 29(4), 492-504.

Gutiérrez Rivera, L. (2013). Territories of Violence: State, Marginal Youth, and Public Security in Honduras. Nueva York: Palgrave Macmillan.

Hazen, J. M. y Rodgers, D. (eds.) (2014). Global Gangs: Street Violence across the World. Mineápolis: University of Minnesota Press.

Hernández León, R. (1999). iA la aventura! Jóvenes, pandillas y migración en la conexión Monterrey-Houston. En G. Mummert (ed.), Fronteras fragmentadas (pp. 115-143). Zamora: El Colegio de Michoacán.

Herrera, E., Jones, G. A. y Thomas de Benítez, S. (2009). Bodies on the Line: Identity Markers among Mexican Street Youth. Children's Geographies, 17(1), 67-81. Holston, J. (2008). Insurgent Citizenship: Disjunctions of Democracy and Modernity in Brazil. Princeton: Princeton University Press.

Hopper, C. B. y Moore, J. (1990). Women in Outlaw Motorcycle Gangs. Journal of Contemporary Ethnography, 18, 363-387.

Hume, M. (2004). "It's as if you don't know, because you don't do anything about it": Gender and Violence in El Salvador. Environment and Urbanization, 16(2), 63-72.

Hume, M. (2007a). (Young) Men with Big Guns: Reflexive Encounters with Violence and Youth in El Salvador. Bulletin of Latin American Research, 26(4), 480-496. 
Hume, M. (2007b). Mano Dura: El Salvador Responds to Gangs. Development in Practice, 17(6), 739-751.

Hume, M. (2009). The Politics of Violence: Gender, Conflict and Community in El Salvador. Oxford: Wiley-Blackwell.

Hume, M. y Wilding, P. (2015). Es que para ellos el Deporte es Matar: Rethinking the Scripts of Violent Men in El Salvador and Brazil. En J. Auyero, P. Bourgois y N. Schepper-Hughes (eds.), Violence at the Urban Margins (pp. 93-111). Oxford: Oxford University Press.

Jones, G. A. (2014). "Hecho en México": Gangs, Identities and the Politics of Public Security. En J. M. Hazen y D. Rodgers (eds.), Global Gangs: Street Violence across the World (pp. 255-280). Mineápolis: University of Minnesota Press.

Jones, G. A. y Rodgers, D. (eds.) (2009). Youth Violence in Latin America: Gangs and Juvenile Justice in Perspective. Nueva York: Palgrave Macmillan.

Jones, G. A. y Rodgers, D. (2011). The World Bank's World Development Report 2011 on Conflict, Security, and Development: A Critique through Five Vignettes. Journal of International Development, 23(7), 980-995.

Jones, G. A. y Rodgers, D. (2015). Gangs, Guns, and the City: Urban Policy in Dangerous Places. En C. Lemanski y C. Marx (eds.), The City in Urban Poverty (pp. 205-226). Londres: Palgrave.

Jones, N. P. (2013). Understanding and Addressing Youth in "Gangs" in Mexico. Recuperado de https://www.wilsoncenter.org/sites/default/files/jones_youth_gangs. pdf

Jütersonke, O., Muggah, R. y Rodgers, D. (2009). Gangs, Urban Violence, and Security Interventions in Central America. Security Dialogue, 40(4-5), 373-397. Kruijt, D. y Koonings, K. (eds.) (1999). Societies of Fear: The Legacy of Civil War, Violence and Terror in Latin America. Londres: Zed Books.

Leeds, E. (1996). Cocaine and the Parallel Polities in the Brazilian Urban Periphery: Constraints on Local-Level Democratization. Latin American Research Review, $31(3), 47-83$.

Leeds, E. (2007). Rio de Janeiro. En K. Koonings y D. Kruijt (eds.), Fractured Cities: Social Exclusion, Urban Violence and Contested Spaces in Latin America. Londres: Zed Books.

Levenson, D. (1988). Por sí mismos: un estudio preliminar de las "maras" en la ciudad de Guatemala. Guatemala: Asociación para el avance de las Ciencias Sociales en Guatemala (Avancso).

Levenson, D. (2013). Adiós Niño: The Gangs of Guatemala City and the Politics of Death. Durham: Duke University Press. 
Lewis, O. (1961). The Children of Sánchez: Autobiography of a Mexican Family. Nueva York: Random House.

Macaulay, F. (2007). Knowledge Production, Framing and Criminal Justice Reform in Latin America. Journal of Latin American Studies, 39(3), 627-651.

Mateo, C. y González, C. (1998). Bandas juveniles: violencia y moda. Revista Venezolana de Análisis de Coyuntura, 4(1), 229-247.

Merino, J. (2001). Las maras en Guatemala. En ERIC, Ideso, Idies e Iudop (eds.), Maras y pandillas en Centroamérica (Vol. 1) (pp. 109-218). Managua: UCA Publicaciones.

Moser, C. O. N. (2009). Ordinary Families, Extraordinary Lives: Assets and Poverty Reduction in Guayaquil, 1978-2004. Washington: Brookings Institution Press.

Muggah, R. y Souza Mulli, A. (2012). Rio tries counterinsurgency. Current History, 111(742), 62-66.

Nateras Domínguez, A. (2006). Violencia simbólica y significación de los cuerpos: tatuajes en jóvenes. Revista Temas Sociológicos, 11, 71-101.

Nateras Domínguez, A. (2007). Adscripciones juveniles y violencias transnacionales: cholos y maras. En J. M. Valenzuela Arce, A. Nateras Domínguez y R. Reguillo Cruz (eds.), Las maras: identidades juveniles al límite. México D. F.: Universidad Autónoma Metropolitana Iztapalapa.

Noche y Niebla. (2002). Caso tipo 2: Comuna 13, la otra versión. Bogotá: Cinep, Justicia y Paz.

Núñez, J. C. (1996). De la ciudad al barrio: redes y tejidos urbanos en Guatemala, El Salvador y Nicaragua. Guatemala: Universidad Rafael Landivar, PROFASR.

O'Donnell, G. (1993). On the State, Democratization, and some Conceptual Problems: A Latin American View with Glances at some Post-Communist Countries. World Development, 21(8), 1355-1369.

O'Neill, K. L. (2010). The Reckless Will: Prison Chaplaincy and the Problem of Mara Salvatrucha. Public Culture, 22(1), 67-88.

O’Neill, K. L. (2011). Delinquent Realities: Christianity, Formality, and Security in the Americas. American Quarterly, 63(2), 337-365.

O’Neill, K. L. (2012). The Soul of Security: Christianity, Corporatism, and Control in Postwar Guatemala. Social Text, 30(2/111), 21-42.

Pearce, J. (1998). From Civil War to "Civil Society": Has the End of the Cold War brought Peace to Central America? International Affairs, 74(3), 587-615.

Pedrazzini, Y. y Sánchez, M. R. (1992). Malandros, bandas y niños de la calle: cultura de urgencia en las metrópolis latinoamericanas. Valencia, Caracas: Vadell Hermanos Editores. 
Penglase, R. B. (2005). The Shutdown of Rio de Janeiro: The Poetics of Drug Trafficker Violence. Anthropology Today, 21(5), 3-6.

Penglase, R. B. (2008). The Bastard Child of the Dictatorship: The Comando Vermelho and the Birth of "Narco-Culture" in Rio de Janeiro. The Luso-Brazilian Review, 45(1), 118-145.

Penglase, R. B. (2009). States of Insecurity: Everyday Emergencies, Public Secrets and Drug Trafficker Power in a Brazilian Favela. PoLAR: Political and Legal Anthropology Review, 32(1), 407-423.

Perea Restrepo, C. M. (2007). Con el diablo adentro: pandillas, tiempo paralelo y poder. México D. F.: Siglo Veintiuno Editores.

Perea Restrepo, C. M. (2008). Pandillas: muerte y sentido. Urvio: Revista latinoamericana de Seguridad Ciudadana, 4, 23-34.

Perlman, J. (2009). Megacity's Violence and its Consequences in Rio de Janeiro.

En K. Koonings y D. Kruijt (eds.), Mega-Cities: The Politics of Urban Exclusion and Violence in the Global South (pp. 52-68). Londres: Zed Books.

Perlman, J. (2010). Favela: Our Decades of Living on the Edge in Rio de Janeiro. Oxford: Oxford University Press.

Queirolo Palmas, L. (2009). Pandillas en el Atlántico latino: identidad, transnacionalismo y generaciones. Iconos, 34, 125-138.

Ranum, E. C. (2011). Street Gangs of Guatemala. En T. Bruneau, L. Dammert y E. Skinner (eds.), Maras: Gang Violence and Security in Central America (pp. 70-86). Austin: University of Texas Press.

Reguillo, R. (1991). En la calle otra vez: las bandas. Identidad urbana y usos de la comunicación. Guadalajara: Iteso.

Riaño-Alcalá, P. (2006). Dwellers of Memory: Youth and Violence in Medellin, Colombia. New Brunswick: Transaction Publishers.

Rocha, J. L. (2000a). Pandilleros: la mano que empuña el mortero. Envío, (216), 17-25.

Rocha, J. L. (2000b). Pandillas: una cárcel cultural. Envío, (219), 13-22.

Rocha, J. L. (2003). Tatuajes de pandilleros: estigma, identidad y arte. Envío, (258), 42-50.

Rocha, J. L. (2005). El "traído": clave de la continuidad de las pandillas. Envío, (280), 35-41.

Rocha, J. L. (2007a). Lanzando piedras, fumando "piedras": evolución de las pandillas en Nicaragua 1997-2006. Managua: UCA Publicaciones.

Rocha, J. L. (2007b). Del telescopio al microscopio: hablan tres pandilleros. Envio, (303), 23-30. 
Rocha, J. L. (2008a). Pandillas y religión: más de un vínculo y más de dos. Envio, (314), 18-23.

Rocha, J. L. (2008b). La Mara 19 tras las huellas de las pandillas políticas. Envío, (321), 26-31.

Rocha, J. L. (2010). Un debate con muchas voces: pandillas y Estado en Nicaragua. Temas, 64, 9-37.

Rocha, J. L. (2013). Violencia juvenil y orden social en el Reparto Schick: juventud marginada y relación con el Estado. Washington: Inter-American Development Bank.

Rocha, J. L. y Rodgers, D. (2008). Bróderes descobijados y vagos alucinados: una década con las pandillas nicaragüenses, 1997-2007. Managua: Envío.

Rodgers, D. (1997). Un antropólogo-pandillero en un barrio de Managua. Envío, (184), 10-16.

Rodgers, D. (1999). Youth Gangs and Violence in Latin America and the Caribbean: A Literature Survey. Washington: World Bank.

Rodgers, D. (2000). Living in the Shadow of Death: Violence, Pandillas, and Social Disintegration in Contemporary Urban Nicaragua. (Tesis doctoral inédita). University of Cambridge, Reino Unido.

Rodgers, D. (2003). Youth Gangs in Colombia and Nicaragua: New Forms of Violence, New Theoretical Directions? En A. Rudquivst (ed.), Breeding Inequality. Reaping Violence: Exploring Linkages and Causality in Colombia and Beyond (pp. 111-141). Upsala: Collegium for Development Studies, Uppsala University.

Rodgers, D. (2006a). Living in the Shadow of Death: Gangs, Violence, and Social Order in Urban Nicaragua, 1996-2002. Journal of Latin American Studies, 38(2), 267-292.

Rodgers, D. (2006b). The State as a Gang: Conceptualising the Governmentality of Violence in Contemporary Nicaragua. Critique of Anthropology, 26(3), 315-330. Rodgers, D. (2007a). Joining the Gang and becoming a Broder: The Violence of Ethnography in Contemporary Nicaragua. Bulletin of Latin American Research, 26(4), 444-461.

Rodgers, D. (2007b). When Vigilantes turn Bad: Gangs, Violence, and Social Change in Urban Nicaragua. En D. Pratten y A. Sen (eds.), Global Vigilantes (pp. 349-370). Londres: Hurst.

Rodgers, D. (2009). Slum Wars of the 21st Century: Gangs, Mano Dura, and the New Urban Geography of Conflict in Central America. Development and Change, 40(5), 949-976.

Rodgers, D. (2010). Génèse d'un gangster? De la pandilla au cartelito au Nicaragua post-Sandiniste. Problèmes d'Amérique Latine, 76, 61-76. 
Rodgers, D. (2012). Nicaragua's Gangs: Historical Legacy or Contemporary Symptom? NACLA Report on the Americas, 45(1), 66-69.

Rodgers, D. (2013). Broderes in Arms: Gang Socialization in Post-Conflict Nicaragua. Vancouver: Simon Fraser School of International Studies.

Rodgers, D. (2015a). The Moral Economy of Murder: Violence, Death, and Social Order in Nicaragua. En J. Auyero, P. Bourgois, and N. Schepper-Hughes (eds.), Violence at the Urban Margins (pp. 21-40). Oxford: Oxford University Press.

Rodgers, D. (2015b). Gangland Nicaragua: The Ethnography of Violence and Social Order in Central America. Manuscrito presentado para su publicación.

Rodgers, D. y Muggah, R. (2009). Gangs as Non-State Armed Groups: The Central American Case. Contemporary Security Policy, 30(2), 301-317.

Rodgers, D. y Rocha, J. L. (2013). The Evolution of Gang Violence in Post-Revolutionary Nicaragua. En Small Arms Survey 2013: Everyday Dangers (pp. 48-73). Cambridge: Cambridge University Press.

Rosas, G. (2012). Barrio Libre: Criminalizing States and Delinquent Refusals of the New Frontier. Durham: Duke University Press.

Rozema, R. (2008). Urban DDR-Processes: Paramilitaries and Criminal Networks in Medellín, Colombia. Journal of Latin American Studies, 40(3), 423-452.

Rubio, M. (2007). De la pandilla a la mara: pobreza, educación, mujeres y violencia juvenil. Bogotá: Universidad Externado de Colombia.

Saborio, S. (2013). The Pacification of the Favelas: Mega Events, Global Competitiveness, and the Neutralization of Marginality. Socialist Studies/Études socialistes, 9(2), 130-145.

Salas, L. (1979). Social Control and Deviance in Cuba. Nueva York: Praeger Publishers. Salomón, L., Castellanos, J. y Flores, M. (1999). La delincuencia juvenil: los menores infractores en Honduras. Tegucigalpa: Cedoh.

Santacruz Giralt, M. L. y Concha-Eastman, A. (2001). Barrio adentro: la solidaridad violenta de las pandillas. San Salvador: Instituto Universitario de Opinión Pública (ludop).

Santillán, A. y Varea, S. (2008). Estrategias y políticas de inclusión (iasimilación?) de pandillas en Ecuador: dos modelos de ciudades, dos visiones sobre las potencialidades de los/as jóvenes pandilleros/as. Urvio: Revista latinoamericana de Seguridad Ciudadana, (4), 81-99.

Savenije, W. (2009). Maras y barras: pandillas y violencia juvenil en los barrios marginales de Centroamérica. San Salvador: Flacso.

Savenije, W. y Andrade-Eekhoff, K. (eds.) (2003). Conviviendo en la orilla: violencia y exclusión social en el área metropolitana de San Salvador. San Salvador: Flacso. 
Scheper-Hughes, N. (2015). Death Squads and Vigilante Politics in Democratic Northeast Brazil Violence as Usual: The Militarization of Everyday Life. En J. Auyero, P. Bourgois y N. Schepper-Hughes (eds.), Violence at the Urban Margins (pp. 266-204). Oxford: Oxford University Press.

Scott, J. C. (1998). Seeing Like a State: How Certain Schemes to Improve the Human Condition Have Failed. New Haven: Yale University Press.

Small Arms Survey. (2010). Small Arms Survey 2010: Gangs, Groups and Guns. Cambridge: Cambridge University Press.

Small Arms Survey. (2013). Small Arms Survey 2013: Everyday Dangers. Cambridge: Cambridge University Press.

Soares, C. E. L. (2001). A capoeira escrava e outras tradições rebeldes no Rio de Janeiro (1808-1850). Campinas: Unicamp.

Soares, L. E., Sé, J. T. S., Rodrigues, J. y Piquet Cerneiro, L. (1996). Violencia e politica no Rio de Janeiro. Río de Janeiro: Editora Relume.

Sosa Meléndez, J. J. (2000). ¿Votaron o no los pandilleros de Managua? Envío, (224), 37-43.

Suárez Rodríguez, C. (2005). Escenarios de homicidios 1990-2002. Estudios Políticos, 26, 185-205.

Sullivan, J. P. (2006). Maras Morphing: Revisiting Third Generation Gangs. Global Crime, 7(3-4), 489-492.

Sullivan, J. P. y Elkus, A. (2009). Global cities-global gangs. Recuperado de http:// www.opendemocracy.net/opensecurity/john-p-sullivan-adam-elkus/globalcities-0E2\%80\%93-global-gangs

Taylor, C. (1990). Dangerous Society. East Lansing: Michigan State University Press. Torres, A. (2006). Pandillas y Naciones en Ecuador: diagnóstico de situación. Boletín Ciudad Segura, (3), 4-9.

Ulloa, L. F. (2004). ¿Por qué no terminamos esto? Diagnóstico de las pandillas juveniles o marimbas de Estelí, con miras a buscar pistas para mejorar la situación. Estelí: Adeso "Las Segovias", Policía Nacional de Estelí.

UNDP. (2013). Human Development Report for Latin America 2013-2014: Citizen Security with a Human Face. Evidence and Proposals for Latin America. Nueva York: UNDP.

UNODC. (2007). Crime and Development in Central America: Caught in the Crossfire. Viena: Unodc.

UNODC. (2014). Global Study on Homicide 2013: Trends, Contexts, Data. Viena: Unodc.

USAID. (2006). Central America and Mexico Gangs Assessment. Washington: Usaid. 
Valdez, A. (2011). The Origins of Southern California Latino Gangs. En T. Bruneau, L. Dammert y E. Skinner (eds.), Maras: Gang Violence and Security in Central America (pp. 23-42). Austin: University of Texas Press.

Vermeij, P. J. (2006). That's Life: Community Perceptions of Informality, Violence, and Fear in Two Spontaneous Human Settlements in Managua, Nicaragua. (Tesis de maestría inédita). Utrecht University, Países Bajos.

Vianna, H. (ed.). (1997). Galeras cariocas: territórios de conflitos e encontros culturais. Río de Janeiro: Editora UFRJ.

Ward, T. W. (2013). Gangsters without Borders: An Ethnography of a Salvadoran Street Gang. Oxford: Oxford University Press.

Weegels, J. (abril, 2014). Transgressing Community: Representations of Youth Crime and Policing on the Nicaraguan Televised News. Ponencia presentada en la Conferencia Anual de la Society for Latin American Studies, Londres, Birkbeck College, University of London.

Winton, A. (2004). Young People's View on how to tackle Gang-Violence in "PostConflict" Guatemala. Environment and Urbanization, 16(2), 83-99.

Winton, A. (2007). Using "Participatory" Methods with Young People in Contexts of Violence: Reflections from Guatemala. Bulletin of Latin American Research, 26(4), 497-515.

Wolf, S. (2012a). El Salvador's Pandilleros Calmados: The Challenges of Contesting Mano Dura through Peer Rehabilitation and Empowerment. Bulletin of Latin American Research, 31(2), 190-205.

Wolf, S. (2012b). Mara Salvatrucha: The Most Dangerous Street Gang in the Americas? Latin American Politics and Society, 54(1), 65-99.

Wolseth, J. (2011). Jesus and the Gang: Youth Violence and Christianity in Urban Honduras. Tucson: University of Arizona Press.

World Bank. (2011). World Development Report: Conflict, Security and Development. Washington: World Bank.

Zaluar, A. (1983). Condomínio do diabo: as classes populares urbanas e a lógica do "ferro e fumo." En P. S. Pinheiro (ed.), Crime, violência e poder (pp. 75-88). São Paulo: Brasiliense.

Zaluar, A. (1994). Condomínio do diabo. Río de Janeiro: Editora Revan/UFRJ.

Zaluar, A. (1997). Gangues, galeras e quadrilhas: globalização, juventude e violência. En H. Vianna (ed.), Galeras cariocas: Territórios de conflitos e encontros culturais (pp. 177-202). Río de Janeiro: Editora UFRJ.

Zaluar, A. (2000). Perverse Integration: Drug Trafficking and Youth in the Favelas of Rio de Janeiro. Journal of International Affairs, 53(2), 654-671. 
Zilberg, E. (2011). Spaces of Detention: The Making of a Transnational Gang Crisis between Los Angeles and San Salvador. Durham: Duke University Press.

Zubillaga, V. (2007). Los varones y sus clamores: los sentidos de la demanda de respeto y las lógicas de la violencia entre jóvenes de vida violenta de barrios en Caracas. Espacio Abierto: Cuaderno Venezolano de Sociología, 16(3), 577-608.

Zubillaga, V. (2009). "Gaining Respect": The Logic of Violence among Young Men in the Barrios of Caracas, Venezuela. En G. A. Jones y D. Rodgers (eds.), Youth Violence in Latin America: Gangs and Juvenile Justice in Perspective (pp. 83-104). Londres: Palgrave.

Zubillaga, V. (2013). Menos desigualdad, más violencia: la paradoja de Caracas. Nueva Sociedad, (243), 104-118.

Zubillaga, V. y Briceño-León, R. (2001). Exclusión, masculinidad y respeto: algunas claves para entender la violencia entre adolescentes en barrios. Nueva Sociedad, (173), 34-78.

Zubillaga, V., Llorens, V. y Souto, J. (2015). Chismosas and Alcahuetas: Being the Mother of an Empistolado within the Everyday Armed Violence of a Caracas Barrio. En J. Auyero, P. Bourgois y N. Schepper-Hughes (eds.), Violence at the Urban Margins (pp. 162-190). Oxford: Oxford University Press. 
